\title{
Modeling climate-smart decision support system (CSDSS) for analyzing water demand of a large-scale rice irrigation scheme
}

\begin{abstract}
Climate projection at local scale is one of the crucial challenges that affects the development of water management-related mitigation plans. Moreover, the currently available climate models do not directly simulate some of the hydro-climatic parameters (e.g., effective rainfall, reference evapotranspiration, irrigation requirements), which are of interest in irrigation sector. Modeling crop-water demands under changing climate involves several step-by-step approaches that are tedious and time-consuming for many water users. This study developed a water management tool, hereafter called Climate-Smart Decision-Support System (CSDSS), for modeling water demand of rice irrigation schemes under climate change impacts. The CSDSS is a user-friendly interactive program consisting of three main modules integrated in MATLAB and a graphical user interface development environment (GUIDE). The model runs with ten Global Climate Models (GCMs) and three emission scenarios (RCP 4.5, 6.0 and 8.5). It can generate several hydro-climatic parameters based on a daily water balance model, with input data from GCMs projections, crop, soil and field conditions. The model allows water managers to make fast decision for paddy water management. The generated outputs can be obtained through individual GCMs as well as through multi-models (ensemble) projection and can be converted into excel format for further analysis. The model was applied to evaluate the impacts of climate change on irrigation water demand and other key hydro-climatic parameters in Tanjung Karang Rice Irrigation Scheme in Malaysia for the period 2010-2099 with reference to the baseline period of 1976-2005. The results show that irrigation water demand will increase during the off-season (January-June) but decrease during the main season (JulyDecember) due to significant contribution from effective rainfall in the latter season. The CSDSS tool can be used for managing water resources under changing climate and would, therefore, be helpful in promoting appropriate adaptation and mitigation strategies that can lead to more sustainable water use at farm level. Some future improvements of the tool, due to methodological limitations of the study, will however improve its performance.
\end{abstract}

Keyword: Rice cultivation; Irrigation water demand; Climate change; Global climate models; Climate-smart DSS 